\title{
Spectroscopic and Phytochemical Examination of Medicinal Plants in Rural Areas of Krishnankoil
}

\author{
M. S. Revathy, K.Gurushankar, K. Rajeswari, Reginold Jebitta, D. Geetha, Naidu Dhanpal \\ Jayram
}

\begin{abstract}
Herbal medicines are part of our daily routine. Usage of synthetic drugs provides instant relief but doesn't give a long term solution. Here we report few medicinal plants of Indigofera Tinctoria, Momordica Cymbalaria, and Withania Somnifera that has been collected in Krishnankoil area of Virudhunagar district in Tamil Nadu. The identification of biomolecules was investigated using fourier transform infrared spectroscopy, Charge transfer between bonding, antibonding, non-bonding was analyzed with $U V$-Vis spectroscopy along with measurement of absorption. Phytochemical testing was carried out inorder to understand the important constituents in the chosen herbals.
\end{abstract}

Keywords : Indigofera Tinctoria, Momordica Cymbalaria, Withania Somnifera, FTIR, UV-Vis Spectroscopy.

\section{INTRODUCTION}

Consumption and utilization of medicinal herbs play a potential therapeutic agent also essential raw ingredients for the manufacturing of several traditional and modern medicines. Phytochemicals with an adequate antibacterial activity are reported for the treatment of bacterial infections. For past decades, about $80 \%$ of Indian medicinal plants have been investigated by researchers from plants are referred to as phytochemicals which are naturally occurring and biologically active compounds that have the potential to prevent diseases. Evaluation of the phytochemical constituents of a medicinal plant is considered to be the main step in medicinal plant research [1]. Traditional plant medicines still enjoy significant position in the modern-day drug industries due to the minor side effects as well as the synergistic action of the combination of compounds [2,3].

Revised Manuscript Received on December 16, 2019.

* Correspondence Author

M.S.Revathy*,Physics, Kalasalingam Academy of Research and Education, Krishnankoil, Virudhunagar, India.

Email: revz.vijay@gmail.com

K.Gurushankar, Physics, Kalasalingam Academy of Research and Education, Krishnankoil, Virudhunagar, India.

Email:kgurumsc@yahoo.com

Email: raji1998.k@gmail.com

Reginold Jebitta, Food Technology, Kalasalingam Academy of Research and Education, Krishnankoil, Virudhunagar, India Email:reginold.s@klu.ac.in.

D.Geetha, Chemistry, Kalasalingam Academy of Research and Education, Krishnankoil, Virudhunagar, India. Email: geethachem2015@gmail.com

Naidu Dhanpal Jayram, Physics, Kalasalingam Academy of Research and Education, Krishnankoil, Virudhunagar, India.

Email: dhanpal.dj@gmail.com for pharmacological activity. Secondary metabolites

K.Rajeswari, Physics, Kalasalingam Academy of Research and Education, Krishnankoil, Virudhunagar, India.

It is most important to create a good herbarium material for taxonomic identification of the collected species, and also cultivation, protection and assessment of germplasm for future use, since amongst the most susceptible plant species in India, the most overexploited are the medicinal plants [4].

The main focus of this study is to motivate the awareness of herbal medicine usage and give a clue of functional group identification for designing drug's efficacy against various diseases by identifying the primary and secondary metabolites present in the various extracts of samples of medicinal plants taken in Krishnankoil and it was investigated by FTIR, UV, and phytochemical studies.

\section{METHODOLOGY}

\section{A.Area Selection}

The study area was taken in Krishnankoil in Virudhunagar district of tamil nadu, India. We have chosen Indigofera Tinctoria (Avuri), Momordica Cymbalaria(Athalakai), Withania Somnifera (Aswagandha) as plant materials for investigation.

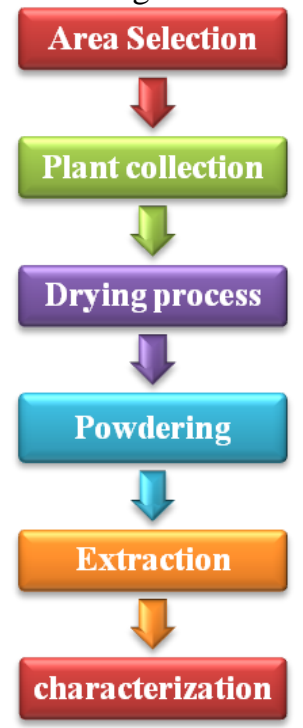

Fig. 1. Flow chart of Methodology

\section{B.Plant Collection}

- Indigofera Tinctoria (IT): A member of Fabaceae family is Indigofera tinctoria. It is enriched with hemostatic, antitoxic, and sedative properties. Cancer, piles, chronic bronchitis, asthma, ulcers, dropsy and hair fall are some curable ailments when supported with I.Tinctoria. Literatures showed that

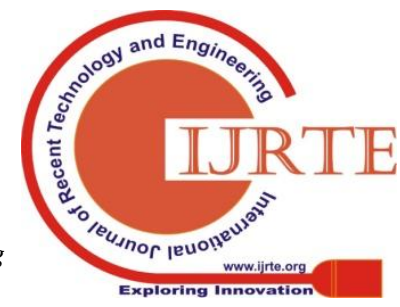


phyotochemical analysis of aqueous extract of this plant contains alkaloids, amino acids, flavonoids, saponins, steroids, glycosides, carbohydrates, tannins, phenolic group and proteins, which are responsible for the antioxidant, antimicrobial and anticancer activities [6].

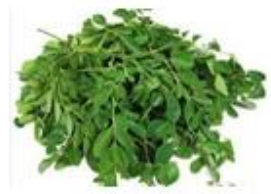

(a)

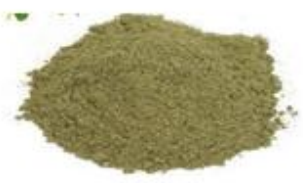

(b)

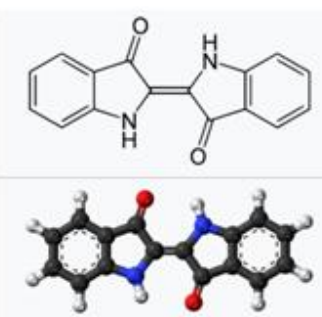

(c)

Fig. 2. (a) Indigofera plant (b) Powdered by mortar (c) Indigo structure

Table- I. Taxonamical classification

\begin{tabular}{|l|l|l|l|}
\hline & IT & MC & WS \\
\hline Kingdom & Plantae & Plantae & Dicotyledons \\
\hline Order & Fabales & Cucurbitales & Tubiflorae \\
\hline Family & Fabaceae & Cucurbitaceae & Solanaceae \\
\hline Genus & Indigofera & Momordica & Withania \\
\hline Species & I. tinctoria & $\begin{array}{l}\text { Momordica } \\
\text { Cymbalaria }\end{array}$ & $\begin{array}{l}\text { Somnifera } \\
\text { Dunal }\end{array}$ \\
\hline
\end{tabular}

- Momordica Cymbalaria(MC): Momordica species (family:Cucurbitaceae - cucumber, gourd, melon or pumpkin family), a medium sized plant with striped fruit grows in abundance at the end of summer season in Krishnankoil. The bitter taste of the fruit is due to the presence of phytochemicals and has broad medicinal values [7]. A Momordica species is an annual or perennial climber that contains about 80 species $[8,9]$. It is noticeable as tonic, stomachic, stimulant, laxative and treats gout, rheumatism, sensitive cases of the spleen as well as liver disease. The powdered form has a benefits of antidiabetic, hypolipidemic and anti-hyperglycemic activities [10,11].The bitter juice and tea from leaf of $M$. cymbalaria treats diabetes, malaria, colic, sores and wounds, infections, worms and parasites, measles, hepatitis, and fevers[12].As a local folk medicine, it also acts as an abortifacient.

- Withania Somnifera: WS (Family: Solanaceae) grows abundantly in India commonly known as Ashwagandha (winter cherry or Indian ginseng or poison gooseberry). It is an imperative medicinal plant that has been used in Ayurvedic and as an indigenous medicine for more than 3,000 years [13].

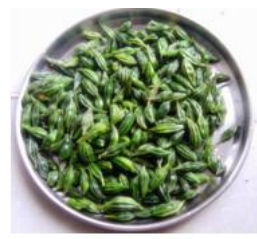

(a)

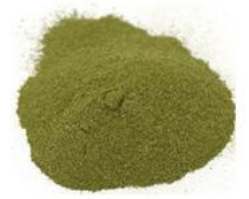

(b)

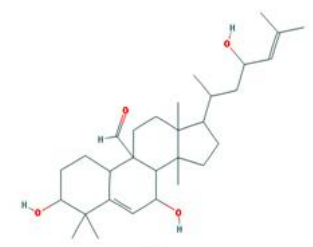

(c)

Fig. 3. (a) Momordica Cymbalaria fruit (b) Powdered by mortar

(c) Momordicin structure

The extract of the plant has a lot of bioactive compounds and thereby exerts antioxidant, anti-inflammatory and immunomodulatory activities.

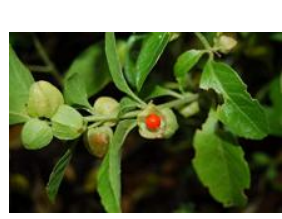

(a)

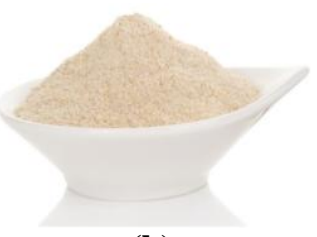

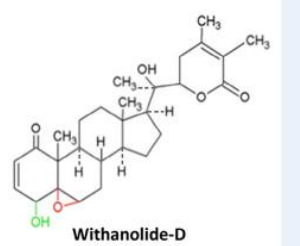

(c) (b)

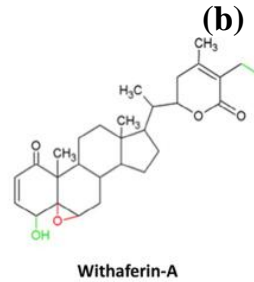

(d)

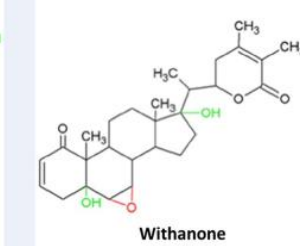

(e)
Fig. 4 (a) Withania Somnifera plant (b) Powdered by mortar (c), (d), (e) Biochemical constituents of Withania structure

\section{C.Drying Process}

The fresh leaves from the chosen plant were collected and then washed several times to remove excess impurities such as dust. The leaves were cut into several tiny pieces and dried for 5 days in shade of a non-dust environment.

\section{D.Powdering}

The dried leaves were grounded into fine powder through agate mortar and for further examination the powder was preserved in an air-tight container.

\section{E. Extraction}

About few grams of the sample was dissolved in a solvent like water and stirred in magnetic stirrer for few hours. The obtained solution was filtered to remove the precipitate using Whatman filter paper 


\section{F. Characterization}

The sample was characterized for the identification of possible functional groups using Shimadzu IT tracer 100 FTIR and relevance of aborption bands, phytochemical studies was carried out and charge transitions detection was done by UV-Vis spectrophotometer.

\section{PRELIMINARY PHYTOCHEMICAL SCREENING}

The phytochemical constituents that play a significant role in medicines can be identified using crude extracts of the plants. Some of them serve as non-nutritive chemicals that can guard humans from various diseases. Based on the function in plant metabolism, phytochemicals are of two main groups, 1) primary and 2) secondary metabolites. Primary metabolites comprise of carbohydrates, amino acids, proteins and chlorophylls, while alkaloids, saponins, steroids, flavonoids and tannins fall under secondary metabolites.

Generally, parts of plants extract contains major/minor phytochemical constituents like triterpenes, proteins, steroids, alkaloids, saponins, flavonoids, steroids, glycosides, carbohydrates, tannins, phenolic compounds and acids. These isolated crude phytochemicals compounds have been used for diverse biological studies of anti diabetic, anti-cancer, anti-viral, anti-diabetic, anti malarial and antimicrobial activities [19].

Following are the chemical tests that were carried out for the extracts of I. Tinctoria, M.Cymbalaria, W.Somnifera to identify the presence of various phytochemical constituents.

\section{A. Test for Alkaloids}

To the plant extract approx. $5 \mathrm{ml}, 2 \mathrm{ml}$ of $\mathrm{HCl}$ was added. In this acidic medium, $1 \mathrm{ml}$ of Dragendroff's reagent was added. Observance of orange or red color shows the presence of alkaloids.

\section{B.Test for Phenols}

Take $2 \mathrm{ml}$ of the plant extract and add $5 \%$ aqueous ferric chloride of $2 \mathrm{ml}$ were added; If there is a presence of phenol, blue color will be present in the sample

\section{Test for Flavonoids}

For flavonoids test, sodium hydroxide (20\%) in few drops were added in the plant extract, When there is a formation of yellow colour, it represents the presence of flavonoids.

\section{Test for Saponins}

To $2 \mathrm{ml}$ of each extract, $6 \mathrm{ml}$ of distilled water were added and shaken vigorously; the creation of bubbles or existence of foam indicates the confirmation of saponins.

\section{E.Test for Carbohydrates}

This test is done with Molisch's reagent and $1 \mathrm{ml}$ of extract. After the addition of reagent, along the side of the tube $1 \mathrm{ml}$ of concentrated sulphuric acid was added slowly. Then the sample was allowed to stand for 2 to $3 \mathrm{~min}$. Red or violet colour formation indicates the presence of carbohydrates.

\section{F. Test for Glycosides}

To identify the presence of glycosides with $1 \mathrm{ml}$ of extract, $0.5 \mathrm{ml}$ of glacial acetic acid and 3 drops of $1 \%$ aqueous ferric chloride solution were added. When there is a formation of brown ring at the interface, the presence of cardiac glycosides in the sample extract is confirmed.

\section{G. Test for Proteins}

To $2 \mathrm{ml}$ of each extract, $1 \mathrm{ml}$ of $40 \%$ sodium hydroxide and $1 \% \mathrm{CuSO}_{4}$ was added in drops; formation of violet colour indicates the presence of peptide linkage molecules in the sample extract.

\section{RESULTS AND DISCUSSION}

\section{A.Fourier Transform Infrared Spectroscopic studies}

The FTIR profile of I.Tinctoria, M.Cymbalaria, and W.Somnifera in Fig. 5 was taken for quality evaluation of herbal foliage under study. The weak band of 1651, 1312 attributes to $\mathrm{C}=\mathrm{C}$ stretching which was due to the presence of Indigo compound present in the leaf powder of I.Tinctoria and C-N stretching of aliphatic amines corresponds to 1070 $\mathrm{cm}^{-1}$. The peak $668 \mathrm{~cm}^{-1}$ in the finger print region may be due to the presence of in-plane symmetrical bending of C-C-C. $512 \mathrm{~cm}^{-1}$ indicates aromatic $=\mathrm{C}-\mathrm{H}$ stretching and sturdily support our assumption that various phytochemical constituents like flavonoids, saponins, steroids, glycosides, alkaloids, amino acids, carbohydrates, tannins and phenolic compounds are present in the material. For M.Cymbalaria fruit powder, strong peak at $3375 \mathrm{~cm}^{-1}$ indicate / high absorption and corresponds to the carboxylic and $\mathrm{OH}$ functional groups, and the absorption could be caused by stretching of free or $\mathrm{H}$-bonded $\mathrm{OH}$ groups[9].The $\mathrm{O}-\mathrm{H}$ (hydrogen bonded alcohols,Phenols) and $2926 \mathrm{~cm}^{-1}$ shows the presence of C-H stretching[10]. The weak band of 1651, 1418 attributes to $\mathrm{C}=\mathrm{C}$ stretching which was due to the presence of Momordicin compound present in the fruit powder of M.Cymbalaria and $\mathrm{C}-\mathrm{N}$ stretching of aliphatic amines corresponds to $1051 \mathrm{~cm}^{-1}$ [11]. The peak $528 \mathrm{~cm}^{-1}$ in the finger print region may be due to the presence of in-plane symmetrical bending of C-C-C. The peaks of 1650, 1051 and $528 \mathrm{~cm}^{-1}$ is in agreement with counterpart of the title compound Momordica Charantia [12].

W. Somnifera fruit powder shows strong peak at 3291 $\mathrm{cm}^{-1}$. The assignable band assignment is $\mathrm{O}-\mathrm{H}$ stretching, indicates the presence of alcohols and phenols. The medium intensity of transmittance at $2356 \mathrm{~cm}^{-1}$ shows C-H stretching indicating alkanes. The band at $1637 \mathrm{~cm}^{-1}$ with strong transmittance intensity shows $\mathrm{C}=\mathrm{C}$ stretching which could be aroused due to alcohol. 


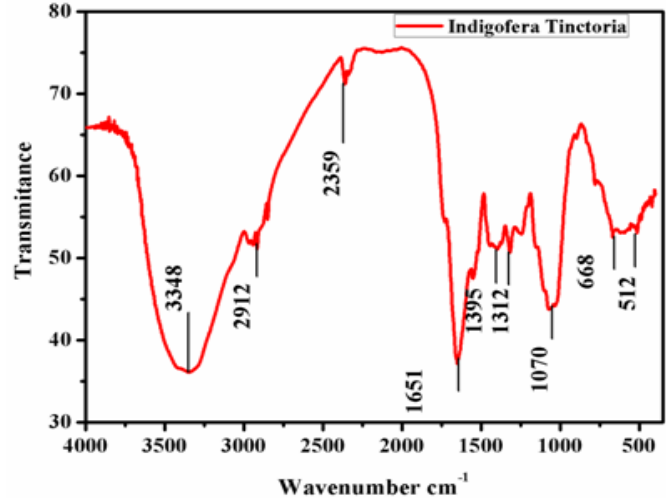

(a)

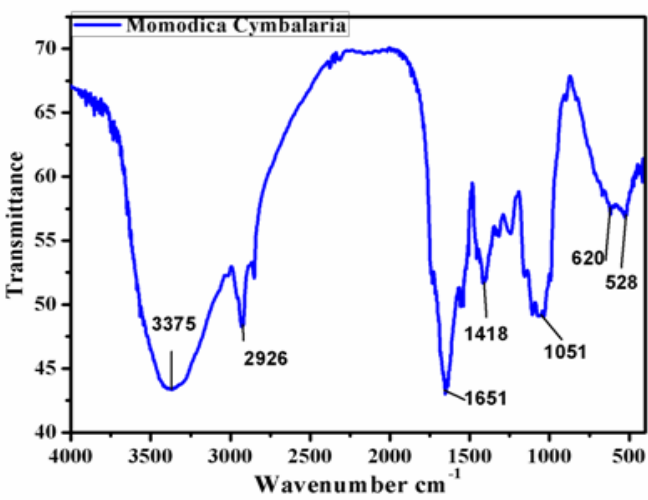

(b)

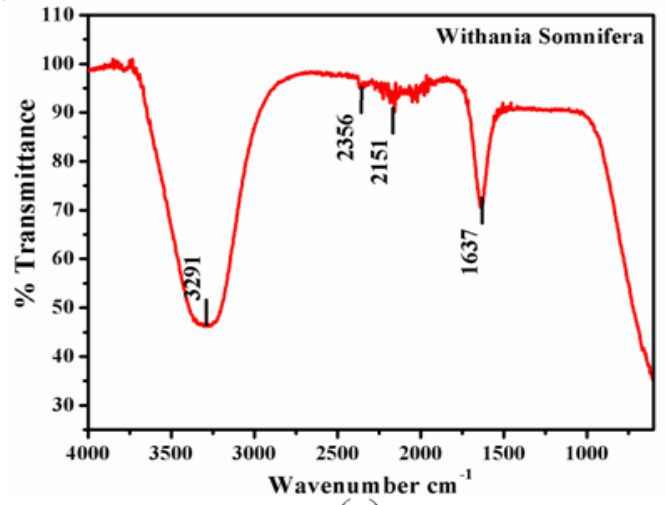

(c)

Fig. 5. FTIR spectra of (a) Indigofera Tinctoria, (b) Momordica Cymbalaria, and (c) Withania Somnifera

Table- II: Band assignments of I. Tinctoria

\begin{tabular}{|l|l|l|l|l|}
\hline Wave number $\mathbf{~ c m}^{-1}$ & Intensity & Strength & Band Assignment & Functional group \\
\hline 3348 & 36 & strong & O-H & Alcohols, Phenols \\
\hline 2912 & 51 & medium & C-H stretching & Alkanes \\
\hline 2359 & 71 & medium & N-H stretching & \\
\hline 1651 & 37 & strong & C=C stretching & Alcohol \\
\hline 1395 & 51 & medium & C=C stretching & Alcohol \\
\hline 1312 & 50 & medium & - & - \\
\hline 1070 & 43 & strong & C-N stretching & aliphatic amines \\
\hline 668 & 53 & medium & C-H Bending & Alkenes \\
\hline 512 & 53 & medium & =C-H stretching & aromatic \\
\hline
\end{tabular}

Table- III: Band assignments of M.Cymbalaria

\begin{tabular}{|l|l|l|l|l|}
\hline Wave number $\mathbf{c m}^{-\mathbf{1}}$ & Intensity & Strength & Band Assignment & Functional group \\
\hline 3375 & 43 & strong & O-H & Alcohols, Phenols \\
\hline 2926 & 48 & medium & C-H stretching & Alkanes \\
\hline 1651 & 43 & strong & C=C stretching & Alcohol \\
\hline 1418 & 51 & strong & C=C stretching & Alcohol \\
\hline 1051 & 49 & strong & C-N stretching & aliphatic amines \\
\hline 620 & 57 & medium & C-H Bending & Alkenes \\
\hline 528 & 56 & medium & =C-H stretching & aromatic \\
\hline
\end{tabular}

Table- IV: band assignments of W.Somnifera

\begin{tabular}{|l|l|l|l|l|}
\hline Wave number $\mathbf{c m}^{-1}$ & Intensity & Strength & Band Assignment & Functional group \\
\hline 3291 & 46 & strong & O-H & Alcohols, Phenols \\
\hline 2356 & 95 & medium & C-H stretching & Alkanes \\
\hline 2151 & 90 & medium & - & - \\
\hline 1637 & 75 & strong & C=C stretching & Alcohol \\
\hline
\end{tabular}




\section{B.Optical Studies}

Optical studies was carried out using UV-Vis spectrophotometer. The analyses of the extract were performed with a dilution of 1:100. Fig. 6. displays the UV spectra of I. Tinctoria, M. Cymbalaria, and W. Somnifera. 3.18 at $266 \mathrm{~nm}$ for I.Tinctoria. It was evident that $220.8 \mathrm{~nm}$ and $266 \mathrm{~nm}$ could be aroused as a result of $\pi \rightarrow \pi^{*}$ transitions and these absorption bands reveal the phenolic compounds. The results showed an absorbance of 0.272 at $272.01 \mathrm{~nm}$ and 0.230 at $272.54 \mathrm{~nm}$ for M.Cymbalaria and it was well was evident that $272.01 \mathrm{~nm}$ and $272.54 \mathrm{~nm}$ could be arised as a result of $\pi \rightarrow \pi^{*}$ transitions which reveal the phenolic compounds. An absorbance of 3.88 at $206 \mathrm{~nm}$ for $W$. Somnifera was well correlated with the results of the literature. $\sigma \rightarrow \sigma *, \mathrm{n} \rightarrow \pi *$, and $\pi \rightarrow \pi *$ are the energy transitions of the singlet to the singlet excited state and its impact was well revealed in UV absorbance. Electronic transitions could have happened when the energy difference between the LUMO (lowest unoccupied molecular orbital) and HUMO (highest occupied molecular orbital) is significantly higher than the activation energy of the compound.

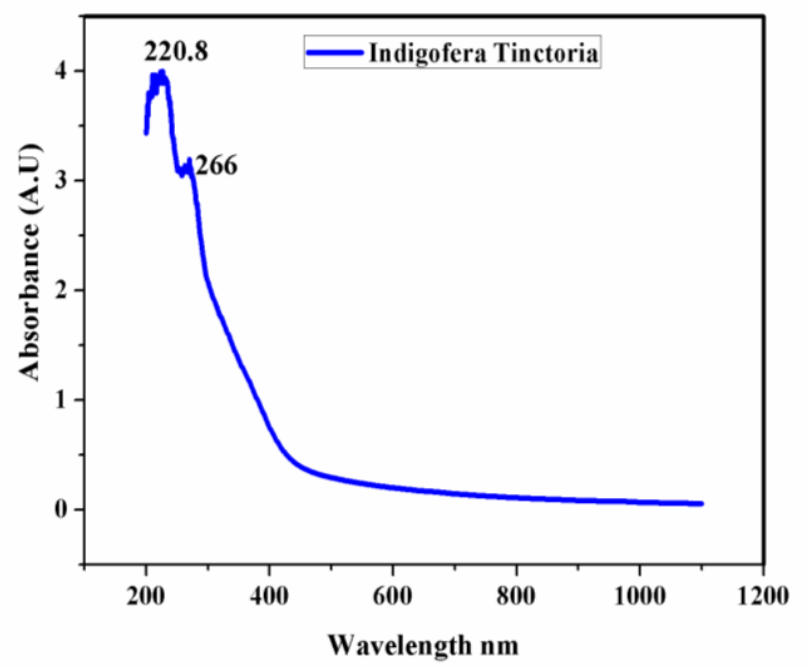

(a)

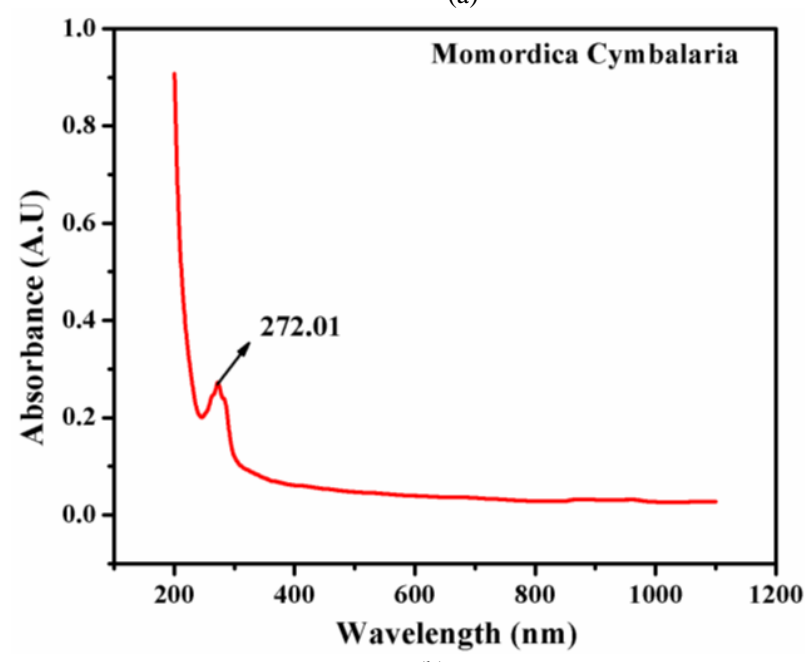

(b) The results showed an absorbance of 3.95 at $220.8 \mathrm{~nm}$ and correlated with the results of Momordica Charantia [14]. It

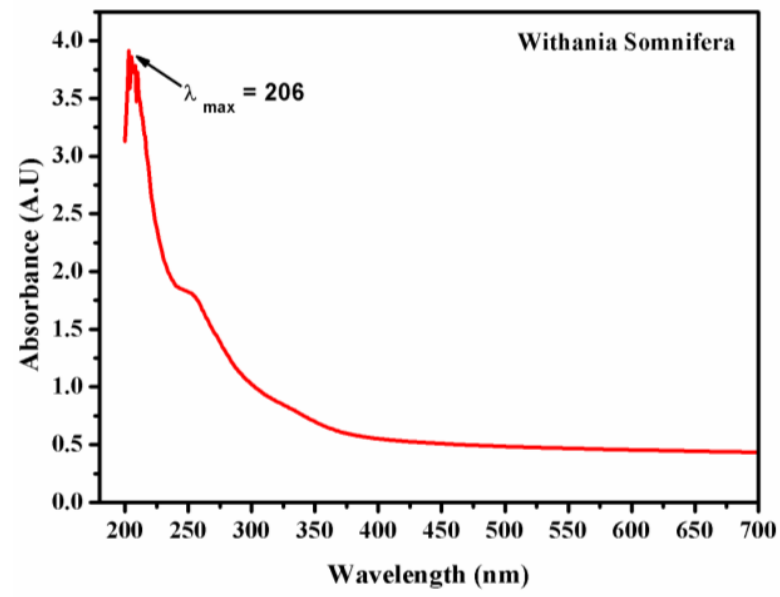

(c)

Fig. 6. UV spectra of (a) Indigofera Tinctoria, (b) Momordica Cymbalaria, and (c)Withania Somnifera

\section{C.Phytochemical Studies}

Various phytochemical testing was done for the prepared solution of 20 grams dissolved in the $200 \mathrm{ml}$ of deionized water which was used as a solvent. The filtered extract was utilized for testing as per testing procedure as mentioned. The following Table-V shows the presence and absence of phenolic, flavanoid, saponin, gum and mucilage, carbohydrate, glucoside, oil and fat. The result clearly shows the presence of phenolic, flavanoid, carbohydrate and glucoside, rest were absent.

Table- V: Qualitative chemical examination

\begin{tabular}{|l|c|c|c|}
\hline Test & IT & MC & WS \\
\hline Phenolic & + & + & - \\
\hline Flavanoid & + & + & - \\
\hline Saponin & - & - & - \\
\hline Gum \& Mucilage & - & - & - \\
\hline Carbohydrate & + & - & + \\
\hline Glucoside & + & - & + \\
\hline Oil \& Fat & - & - & + \\
\hline
\end{tabular}

(+) denotes the presence and (-) denotes the absence of particular class of compounds

\section{CONCLUSION}

This work was done with an aim to identify the bioactive molecules present in the chosen three plants of Indigofera Tinctoria (leaves), Momordica Cymbalaria(fruit) and Withania Somnifera (fruit). Preparation and extraction procedure was detailed in this study and the data from characterization tools (FTIR, optical and phytochemical studies) gave clear evidence regarding active biomolecular vibrational assignments and the corresponding responsible phytochemicals present in the sample. These preliminary studies gave a clue of importance on I. Tinctoria, M. Cymbalaria and W. Somnifera in medicinal field. Apart from relying on synthetic medicines, consumption of traditionality would enhance life span along with the provision of immunity. The future aspects of this work will be further extended in thermal treatment with different solvents, composites, preparation of silver nanoparticles using these 
three plants. The research could pave way for efficacy of drug from these phytoconstituents.

\section{REFERENCES}

1. Haidan Yuan, Qianqian Ma, Li Ye and Guangchun Piao, "The Traditional Medicine and Modern Medicine from Natural Products," Molecules., vol. 21, 2016, pp. 559, doi:10.3390/molecules21050559.

2. Dar RA, Shahnawaz M, Qazi PH. "Natural product medicines: A literature update," J Phytopharmacol., 2017;6(6):349-351.

3. B. Ravishankar, V.J. Shukla, "Indian systems of medicine: a brief profile," Afr J Trad Complem \& Alter Med., vol. 4(3): 2007, pp. 319-337,

4.P.C. Chikezie, O.A. Ojiako, "Herbal Medicine: Yesterday, Today and Tomorrow," Altern Integr Med., vol. 4, pp. 195, 2015. doi: 10.4172/2327-5162.1000195.

5. Jamshidi-Kia F, Lorigooini Z, Amini-Khoei," H. Medicinal plants: past history and future perspective," J Herbmed Pharmacol., vol.7(1), 2018, pp.1-7. doi: 10.15171/jhp.2018.01.

6. Remya Vijayan, Siby Joseph \& Beena Mathew, "Indigofera tinctoria leaf extract mediated green synthesis of silver and gold nanoparticles and assessment of their anticancer, antimicrobial, antioxidant and catalytic properties," Artificial Cells, Nanomedicine, and Biotechnology., vol.46, 2018, pp. 861-871.

7.S. Parvathi, V.J.F. Kumar, "Studies on chemical composition and utilization of the wild edible vegetable athalakkai (Momordica tuberosa)," Plant Foods for Human Nutrition., vol. 57 (3/4), 2002, pp. 215 -222.

8. WHO, "Traditional Medicine: Growing Needs and Potential WHO Policy Perspectives on Medicines,” World Health Organization, Geneva 2002, pp.1-6.

9. T. Murakami, A. Emoto, H. Matsuda H, M.Yoshikawa, "Structures of new cucurbitane-type triterpene glycosides, goyaglycosides-a, -b, -c, -d, -e, -f, - $\mathrm{g}$, and $-\mathrm{h}$, and new oleanane-type triterpene saponins, goyasaponins I, II, and III, from the fruit of Japanese Momordica charantia L," Chem. Pharma. Bullet., vol. 49, 2001, pp. 54-63.

10.R.B. Kameswara, M.M. Kesavulu, C. Apparao, "Evaluation of antidiabetic effect of Momordica cymbalaria fruits in alloxan diabetic rats," Fitoterapia., vol. 74, 2003, pp. 7-13.

11.R.B.Kameswara, M.M. Kesavulu, C. Apparao, "Antihyperglycemic activity of Momordica cymbalaria fruits in alloxan diabetic rats," $J$ Ethnopharmacol., vol.78, 2001, pp. 67-71.

12.R. A. Jeyadevi, T. Sivasudha, A. Rameshkumar, B. Sangeetha, D. Arul Ananth, G. Smilin Bell Aseervatham, "Nutritional constituents and medicinal values of Momordica cymbalaria (Athalakkai) - A review," Asian Pacific Journal of Tropical Biomedicine.,vol 2(1), 2012, pp. S456-S461.

13.M.Umadevi, R. Rajeshwari, C. Rahale Sharmila, S. Selvavenkadesh, R. Pushpa, K.P. Kumar Sampath, D. Bhowmik, "Traditional and medicinal uses of Withania somnifera," The Pharma Innovation., vol.9, 2012, pp. $102-110$.

14.C. Hsu, 1997, Infrared Spectroscopy. In "Handbook of Instrumental Techniques for Analytical Chemistry," F.A. Settle ed, Prentice Hall, Upper Saddle River, NJ, pp. 247-283.

\section{AUTHORS PROFILE}

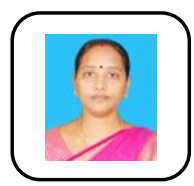

M.S.Revathy, has completed her Ph.D in Anna University in 2016. She has done M.Sc., M.Phil Physics in Mother Teresa Women's University, Kodaikanal. Currently working as Assistant Professor in Department of Physics, Kalasalingam Academy of Research and Education and her field of interests are thin films and green synthesis of nanomaterials. She has published 6 papers in international journals.

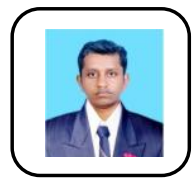

K. Gurushankar has completed M.Sc. and M.Phil., Ph.D. from Annamalai University Chidambaram in 2015. Joined as Assistant Professor at Kalasalingam University from June 2016 onwards. His fields of interest are "Applied spectroscopy in biological field". He has published 12 papers in leading International Journals.

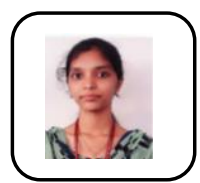

K.Rajeswari has completed her under-graduation in physics during April 2019 in Kalasalingam Academy of Research and Education and now pursuing her post graduation in Physics from the same institution.

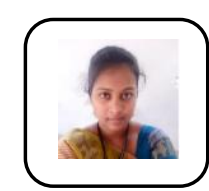

S.Reginold Jebitta has completed M.Tech, Ph.D in Food processing engineering from Karunya institute of technology in 2018. She is an Assistant Professor in Kalasalingam University from April 2017 onwards. Her field of interest is in drying studies and shelf life studies. She has published 7 papers in leading International and National Journals.

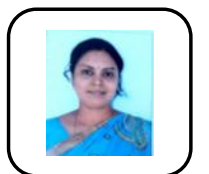

D.Geetha has completed M.Sc in Chemistry discipline from Bharathidasan University, M. Phil., from Annamalai University. She completed Ph. D from Jaypee University in 2016. She is currently working as an Assistant professor at Kalasalingam Academy of Research and Education from 2017 onwards. Her field of interest is bio surfactant. She has published 7 papers in reputed international journals.

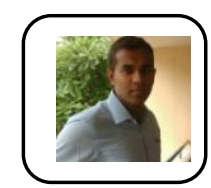

Naidu Dhanpal Jayram is working as Assistant Professor in Department of physics, Kalasalingam Academy of Research and Education. His Research interests are thin films and nanomaterials. His specific area of research is development of substrates for Surface Enhanced Raman Spectroscopy. He has obtained his doctorate degree from Bharathiar University, Coimbatore, Tamil Nadu. He is a recipient of National Postdoctoral fellowship and completed Postdoc from Indian institute of science, Bangalore. He has published 9 papers in international journals and 3 papers in conferences. 